\title{
The Mediating Role of Metacognitive Processes in the Relationship between Personality Traits and Academic Achievement of University Students*
}

\begin{abstract}
Ahmet SAPANCI**
Ali GÜLER ${ }^{* * *}$

Abstract. Academic achievement, which has a critical role in preparing students for their future careers and being successful in many competitive fields, is undoubtedly one of the most important outcomes of their formal education life. For this reason, researches are conducted on many internal and external factors that contribute to the academic achievement of students. In this study, the mediating role of metacognitive processes in the relationship between university students' personality traits such as responsibility, openness to experience, agreeableness, neuroticism and extraversion and academic achievement was tested. Structural equation modeling was used in the research. The population of the research includes students attending the faculty of education of a state university located in the west of Turkey. The sample consisted of 1207 students determined by stratified sampling method. The Metacognitive Awareness Inventory developed by Schraw and Dennison (1994) and adapted into Turkish by Akın, Abacı and Çetin (2007) to measure students' metacognition in the study and the Adjective-Based Personality Test developed by Bacanll, İhan, and Aslan (2007) was used to measure students' personality traits. The personal information form developed by the researcher was used for demographic information and the general academic grade point average was used to determine the academic achievement of the students. As a result of the research, emotional instability and agreeableness dimensions of personality have a negative and significant relationship with metacognition; openness to experience and responsibility factors have a positive and significant relationship with metacognition. On the other hand, it was found that extraversion did not have a significant relationship with metacognition. It was determined that there was a positive and significant relationship between metacognition and academic achievement. The research hypothesis that metacognition plays a mediating role in the relationship between university students' personality traits such as responsibility, openness to experience, agreeableness, neuroticism and academic achievement has been confirmed. Factors other than extraversion of personality traits affect students' metacognition, and metacognition affects academic success. The relationship between personality and academic achievement is established through metacognition.
\end{abstract}

Keywords: Personality, metacognition, academic achievement

\footnotetext{
${ }^{*}$ This article was produced from the doctoral thesis entitled "A structural Equation Modeling of Personality, Metacognition and Academic Achievement and Differences of Learning Styles for Achievement" conducted by Ahmet Sapancı under the supervision of Prof. Dr. Ali Güler at the Institute of Educational Sciences at Abant İzzet Baysal University.

Ethics committee approval for this study was obtained from Düzce University Scientific Research and Publication Ethics Committee, dated 26.08.2021 and numbered 2021/203.

** Orcid ID: https://orcid.org/0000-0003-4688-6890, Assist. Prof. Dr., Düzce University, Turkey, ahmetsapanci@duzce.edu.tr

${ }^{* * *}$ Orcid ID: https://orcid.org/0000-0003-4405-2104, Prof. Dr., Turkey, ali.guler4414@gmail.com
}

Sapancl, A., \& Güler, A. (2021). The Mediating Role of Metacognitive Processes in the Relationship between Personality Traits and Academic Achievement of University Students. Sakarya University Journal of Education, 11(3), 501-525. doi: https://doi.org/10.19126/suje.974304 


\section{INTRODUCTION}

It is critical to identify the internal and environmental aspects that influence students' learning processes when creating learning procedures based on individual differences. There has been an upsurge in the number of studies studying the direct or indirect correlations between people's personality qualities and their academic success in recent years. However, there are some inconsistent findings in previous research on the relationships between personality traits and academic achievement (for example, about the contribution of different personality traits to academic achievement). In addition, these studies did not fully explain the mechanisms responsible for the relationships between personality and academic achievement (Sorić, Penezić, and Burić 2017). Therefore, there is a need for further research on the indirect relationships between personality and academic achievement and on the mediating variables that may play a role in this relationship.

Personality refers to a person's distinct and distinctive representations of thinking, emotion, and action that indicate how he interacts with his physical and social environment (Atkinson, Smith, Bem, \& Nolen-Hoekseama, 1999). Although personality has been defined using various theoretical frameworks, the most widely used personality classification to date is the Five Factor Model (Sleep, Lynam, \& Miller, 2020). Research from the psychometric tradition has established a five-factor personality structure based on factor analysis, including the dimensions of Extraversion, Agreeableness, Conscientiousness, Neuroticism, and Openness to Experience (McCrae \& Costa, 1987). Conscientiousness, which is one of the factors in this theory, which is also called the big five, shows how much control and discipline we have. People at the higher end of this dimension are organized, determined, and plan-driven. Those at the low end are easily distracted and unreliable (Arthur \& Graziano, 1996, as cited in Burger, 2006). Individuals with high responsibility characteristics are expected to have a high tendency to regulate their own efforts and a high desire to succeed. While many researchers report being cautious, orderly and meticulous, organizational skills, high ego control and goal orientation on the positive end of this dimension, they put difficulty in impulse control at the opposite end (Conley, 1985; Johnson \& Ostendorf, 1993; Paunonen, Jackson, Forsterling, \& Trzebinski, 1992; Trapnel and Wiggins, 1990, as cited in Somer, Korkmaz and Tatar, 2004).

Another of the Big Five dimensions, neuroticism, positions people on a scale of emotional stability and personal harmony. People who experience emotional distress and are overly volatile will score high on the neuroticism dimension. People with high levels of neuroticism experience more stress in the face of daily events than people with low levels of neuroticism (Guthert, Cohen, \& Armeli, 1999; Suls, Green, \& Hillis, 1998, as cited in Burger,2006). Individuals having low score in this dimension are calm, welladjusted, and not prone to excessive and maladaptive emotional reactions (Burger, 2006). 
Another factor, called openness to experience or intelligence, has characteristics such as being open-minded, being broad-minded versus being narrow-minded, being intellectual, enlightened, curious and researching (McCrae \& Costa, 1988).

On the other hand, those who score high on the agreeableness or compatibility dimension are helpful, reliable, and compassionate. At the other end of this dimension are hostile and suspicious people. Compatible people prefer cooperation to competition. People with low compatibility are willing to fight for their interests and beliefs. Researchers state that compliant people have more pleasant social relationships and experience fewer fights than non-compliant people (Berry \& Hansen, 2000; Cote \& Moskowitz, 1998; Jensen-Campbell \& Graziano, 2001, as cited in Burger, 2006).

McCrae and Costa (1988) point out that people who score high in the agreeableness dimension are people who love others, are giving and have social interests, but being too advanced in this dimension will represent a neurotic tendency such as 'acting in the direction of others'. The authors state that mild-mannered individuals tend to avoid sensation-seeking, use inversion and rationalization-type defense mechanisms, prefer teaching and social work-type jobs, and are less likely to have coronary heart disease.

The final factor of the Big Five is extroversion. This dimension has extreme extroverts at one end and introverts at the other. Extroverts are highly social people; they are also energetic, optimistic, friendly and sociable. Introverts don't usually show these traits, but it would be wrong to say that they are asocial and lacking in energy. Introverts are shy rather than cold, independent rather than observant, slow-paced rather than sluggish (Costa; McCrae, 1992).

Metacognition, along with personality factors, is a significant predictor of academic performance since it plays an active role in planning, organizing, and monitoring people' learning. Metacognition is the psychological structures, information, events and processes involved in the control, modification and interpretation of thinking (Wells \& Cartwright-Hatton, 2004).

Metacognition refers to high-level cognitive processes related to learning that include making learning goals, applying suitable problem-solving abilities and techniques, anticipating performance, and modifying the amount of learning (Dunslosky \& Thiede, 1998). In this context, cognition includes perceiving, understanding, remembering and similar mental processes while metacognition emerges as a structure that includes people's own perception, understanding, remembering and thinking about similar mental processes (Garner, Alexander, 1989).

Metacognition can be considered in two dimensions as knowledge of cognition and regulation of cognition. The knowledge of cognition, which is divided into three as explanatory knowledge, procedural knowledge and situational knowledge, is the knowledge that individuals have about their own cognition or about cognition in general and includes at least three different metacognitive awarenesses. Descriptive information is information about the individual and strategies, procedural information is about how to use strategies, while situational information is information about when and why to 
use strategies. Regulating cognition encompasses a range of activities that help students control their own learning. Schraw states that although many regulatory skills are mentioned in the literature, three basic strategies are widely accepted. These are planning, monitoring and evaluation. Planning includes choosing appropriate strategies and using resources appropriately to improve performance; monitoring comprises person's online awareness of cognition and task performance; evaluation is judgment of the adequacy of products and individual learning (Schraw, 1998).

\section{Relationships Between Personality, Metacognition and Academic Achievement}

Although personality and metacognition appear to be diametrically opposed, there are some key parallels between them, such as behavioral diversity in time management and organizing skills. Likewise, considering that metacognition varies widely among individuals, it can be said that personality has an effect on the use of metacognition (Kelly \& Donaldson, 2016). Personality traits play a role in how and at what level metacognitive traits are used. For example, the responsibility factor of personality includes traits such as reliability, ability to plan, organize and persist in success. Individuals with high openness to experience are those who have a positive attitude towards deep and complex, challenging learning experiences, as opposed to being simple and narrow-minded (Barrick \& Mount, 1991). The relationship between extraversion and neuroticism and metacognitive processes is more complex than other personality dimensions. On the one hand, extroversion can facilitate social behaviors such as help seeking and peer learning. On the other hand, it was found that extroverts are weaker in reflective problem solving because they tend to reach cognitive results quickly without focusing enough on the problem (Matthews, 1997). Furthermore, higher education often involves complex tasks that require large investment of resources. The sociability, impulsivity and distraction of the extraversion structure may prevent individuals with this characteristic from regulating time and effort effectively in these tasks (Bidjerano \& Dai, 2007).

The effect of neuroticism on achievement generally tends to be negative rather than positive (Matthews \& Zeidner, 2004). Neuroticism is associated with poor critical thinking skills, analytical ability, and conceptual understanding, possibly because it tends to freeze higher-order cognitive functions. It has been found that individuals with high levels of neuroticism have a superficial approach to their learning processes, that is, they focus on memorizing and superficial features rather than understanding the material studied in a deeper and meaningful way (Entwistle, 1988). In general, there are stronger theoretical and empirical justifications for the relationships between selfregulated learning components, including responsibility, openness to experience and amenability, and metacognitive processes, than personality dimensions neuroticism and extraversion (Bidjerano \& Dai, 2007).

In a meta-analysis study in which the most comprehensive statistical analysis of the relationships between personality and academic performance was conducted, Poropat (2009) found that the relationship between academic performance and the 
responsibility dimension of personality was moderate $(d=.46)$, associations with openness $(d=.24)$ and agreeableness $(d=.14)$ corresponded to minor effects, while associations with emotional instability and extraversion were relatively insignificant, taking Cohen's effect size coefficient as a criterion. According to the results of the metaanalysis, responsibility has the highest relationship with academic achievement among all personality dimensions (Poropat, 2009).

Individual cultural, ethnic, and psychological qualities, as well as the contextual characteristics of the classroom setting, have an impact on success and learning. Selfregulatory activities, such as metacognition, in which individuals monitor and control their own cognition, can mediate between personal and contextual characteristics and actual achievement or performance. Self-regulated learning, which includes metacognitive processes, is an active, constructivist process in which learners set their own learning goals and then try to monitor, regulate and control their own cognition, motivation and behavior (Pintrich, 2000).

Personality qualities play a role in the utilization of self-regulatory processes, including metacognition, according to the relevant literature. Personality and metacognition together play a critical role in predicting academic success. Within the scope of all these explanations, in this research, the hypothesis that individuals' personality traits will affect metacognitive mechanisms, and that metacognitive mechanisms will affect academic achievement, in other words, the relationship between personality dimensions and academic achievement will result through metacognitive processes will be tested.

\section{METHOD}

\section{Research Design}

In this study, Structural Equation Modeling was used to determine the mediating role of metacognition in the relationship between personality traits and academic achievement of university students. In the research, a two-stage approach, which is often recommended in the relevant literature, was used to detect and eliminate errors that may arise from the measurement model in structural equation studies. In the first stage, a measurement model whose validity was tested with high-level (second-level) confirmatory factor analysis was created. In the second stage, a structural model was put forward by testing the structural relationships between the latent variables in the measurement model.

\section{Population and Sample}

Ethics committee approval for this study was obtained from Düzce University Scientific Research and Publication Ethics Committee, dated 26.08.2021 and numbered 2021/203. The population of this study consisted of Abant İzet Baysal University Faculty of Education students, and the sample consisted of 1207 students who continued their education in this faculty in the 2008-2009 academic year. In the research, stratified sampling method was used in order to ensure the representation of all departments in 
the education faculty. Stratified sampling is a sampling method in which subgroups in the population are guaranteed to be represented in the sample. For this purpose, first of all, the population is divided into two or more strata (sub-populations), and then a simple unbiased sample is taken from each stratum, and the sub-samples are combined to obtain the total sample (Balcl, 2009). The distribution of the students forming the sample of the study by department, class and gender is given in Table 1 .

Table 1

Descriptive analysis of the Sample

\begin{tabular}{lll}
\hline Department & $\mathrm{f}$ & $\%$ \\
\hline Computer and Instructional Teaching & 87 & 7.2 \\
Classroom Teaching & 125 & 10.4 \\
Counseling and Psychology Teaching & 113 & 9.4 \\
Special Education & 95 & 7.9 \\
Turkish Language Teaching & 131 & 10.9 \\
English Language Teaching & 86 & 7.1 \\
Social Sciences Teaching & 101 & 8.4 \\
Preschool Teaching & 119 & 9.9 \\
Mathematics Teaching & 85 & 7.0 \\
Science Teaching & 108 & 8.9 \\
Music Teaching & 84 & 7.0 \\
Art Teaching & 73 & 6.0 \\
\hline Grade Level & f & $\%$ \\
\hline 1 & 350 & 29.0 \\
2 & 349 & 28.9 \\
3 & 293 & 24.3 \\
4 & 215 & 17.8 \\
\hline Gender & f & $\%$ \\
\hline Male & 427 & 35.4 \\
Female & 780 & 64.6 \\
\hline
\end{tabular}

As seen in Table 1, the participants consisted of 1207 pre-service teachers, 247 of which are male and 780 of which are female, continuing their undergraduate education in 12 different departments. The ages of the participants changed between 17 and 31, with a mean of 20.87 and a standard deviation of 1.82 . 


\section{Data Collection Tools Used in The Research}

Information about the psychometric properties of the measurement tools used in the research is presented below.

\section{Metacognitive Awareness Inventory (MAI)}

In this study, the Metacognitive Awareness Inventory (MAI), which was developed by Schraw and Dennison (1994) and adapted into Turkish by Akın, Abacı and Çetin (2007), was used to measure metacognition. The MAI, which is a 5-point Likert-type scale scored as never $=1$, rarely $=2$, often $=3$, usually $=4$, and always $=5$, consists of a total of 52 items and 8 sub-dimensions. MAI's internal consistency reliability coefficients were .95 for the entire scale, .87 for explanatory information, .83 for procedural information, .80 for situational information, .78 for planning, .75 for monitoring, .73 for evaluation, .73 for debugging. 70 and .66 for information management (Akın, Abacl, Çetin, 2007).

\section{Adjective-Based Personality Test (ABPT)}

The Adjective-Based Personality Test (ABPT), developed by Bacanl, İlhan and Aslan (2007) based on the Five Factor Personality Theory, was used to measure the personality traits of the students. In the scale consisting of bipolar adjectives such as introverted-extroverted, calm-irritable, vindictive-forgiving, the participants mark a situation close to their own personality traits. The internal consistency coefficients of the factors of the scale, which consists of a total of 40 items and 5 dimensions, ranged from .73 to .89. The highest internal consistency coefficient belongs to extraversion (.89), and the lowest internal consistency coefficient belongs to emotional instability (.73). According to the findings of the retest of the scale, the highest correlation was found to belong to agreeableness $\left(r=.86^{* *}, \mathrm{p}<.01\right)$, and the lowest relationship was found to belong to openness to experience dimension $\left(\mathrm{r}=.68^{* *}, \mathrm{p}<.01\right)$. The obtained values show that the scale is a reliable tool.

\section{Measuring Academic Success}

In this study, the overall academic grade point average (GPA) of all the courses taken by the students during the undergraduate period was used as the indicator of academic success, not the grades received from any course.

\section{Personal Information Form}

In the personal information form developed by the researcher, there are questions to collect the introductory information of the participants such as age, gender, department, class.

\section{Data Collection and Analysis}

All data collected within the scope of the research were collected face to face by the researcher. The data collected from a total of 1217 students were transferred to the computer and the scales of 10 participants who were determined to have given incomplete and incorrect answers as a result of the pre-checks were excluded from the 
analysis, and analyzes were carried out with the data of 1207 participants. SPSS and Lisrel programs were used in data analysis. The preconditions required for the confirmatory factor analysis and path analysis, such as normality, linearity, covariance, absence of multicollinearity, independence of residuals, and absence of extreme values, were checked and the analyzes were performed after seeing that there was no violation.

\section{FINDINGS}

The researchers used a model test that was built using a two-stage approach. In the first stage, all latent variables in the model were subjected to a confirmatory factor analysis. When defining the latent variables, an observable variable was created by adding the total score of each metacognition factor, and the latent variable was then defined in the same way. For each dimension of the personality variable, plots were created. Three parcels were created in the dimension with high number of items, and two parcels in the other dimensions. The item parceling method is based on a balanced distribution of items with high and low correlations according to the correlations of the items with the total score of their factor. Below, first of all, descriptive statistics of all observed variables and correlations between variables are given, and then the findings related to the measurement model and structural model used in the research are presented.

Descriptive statistics regarding the variables in the research model are given in Table 2.

Table 2

Descriptive Statsitics Related to the Oberved Variables (N=1207)

\begin{tabular}{lll}
\hline & Mean & Standard Deviation \\
\hline METF1 & 30.78 & 4.94 \\
METF2 & 13.91 & 2.92 \\
METF3 & 18.84 & 3.01 \\
METF4 & 24.84 & 4.58 \\
METF5 & 27.61 & 5.05 \\
METF6 & 21.20 & 4.00 \\
METF7 & 18.21 & 3.29 \\
METF8 & 33.73 & 5.18 \\
NEU1 & 13.07 & 4.29 \\
NEU2 & 10.49 & 4.04 \\
EXT1 & 15.80 & 3.74 \\
\hline
\end{tabular}




\begin{tabular}{lll}
\hline EXT2 & 16.23 & 3.23 \\
EXT3 & 15.38 & 3.88 \\
OPEN1 & 22.36 & 4.34 \\
OPEN2 & 22.57 & 4.09 \\
AGRE1 & 16.51 & 3.53 \\
AGRE2 & 17.03 & 3.13 \\
AGRE3 & 17.68 & 3.57 \\
CONS1 & 16.66 & 3.40 \\
CONS2 & 21.61 & 4.08 \\
ACHIE & 2.66 & .44 \\
\hline
\end{tabular}

METF1 $=$ Explanatory knowledge factor of metacognition, METF2 $=$ Procedural knowledge factor of metacognition, METF3= Situational knowledge factor of metacognition, METF4= Planning factor of metacognition, METF5= Monitoring factor of metacognition, METF6= Evaluation factor of metacognition, METF7= Debugging factor of metacognition, METF8= Knowledge management factor of metacognition, NEU1 $=1$. parcel of the personality's emotional instability(neuroticism) factor, NEU2 $=2$. parcel of the personality's emotional instability factor, EXT1 $=1$. parcel of the personality extraversion factor, EXT2 $=2$. parcel of the personality extraversion factor, EXT3 $=3$. parcel of the personality extraversion factor, OPEN $1=1$. parcel of personality openness factor, $\mathrm{OPEN} 2=2$. parcel of personality openness factor, AGRE1 1 . parcel of personality agreeableness factor, AGRE2 $=2$. parcel of personality agreeableness factor, AGRE3 $=3$. parcel of personality agreeableness factor, CONS1 $=1$. parcel of the personality's responsibility factor, $\mathrm{CONS} 2=2$. parcel of the personality's responsibility factor, $\mathrm{ACHIE}=$ overall academic grade point average

The Pearson Moments Correlation values for the relationships between the observed variables in the research model are presented in Table 3. 
Table 3

Correlations Among the Observed Variables

\begin{tabular}{|c|c|c|c|c|c|c|c|c|c|c|c|c|c|c|c|c|c|c|}
\hline & 1 & 2 & 3 & 4 & 5 & 6 & 7 & 8 & 9 & 10 & 11 & 12 & 13 & 14 & 15 & 16 & 17 & 18 \\
\hline 1.MET5P1 & 1 & & & & & & & & & & & & & & & & & \\
\hline 2.MET5P2 & $.70^{* *}$ & 1 & & & & & & & & & & & & & & & & \\
\hline 3.MET5P3 & $.76^{* *}$ & $.71^{* *}$ & 1 & & & & & & & & & & & & & & & \\
\hline 4.MET5P4 & $.76^{\prime \prime}$ & $.73^{*}$ & $.79^{* *}$ & 1 & & & & & & & & & & & & & & \\
\hline 5.MET5P5 & $.73^{*}$ & $.71^{*}$ & $.79^{* *}$ & $.77^{* *}$ & 1 & & & & & & & & & & & & & \\
\hline 6.NEU1 & $-.18^{* *}$ & $-.22^{* *}$ & $-.21^{* *}$ & $-.21^{* *}$ & $-.22^{* *}$ & 1 & & & & & & & & & & & & \\
\hline 7.NEU2 & $-.11^{* *}$ & $-.12^{* *}$ & $-.12^{* *}$ & $-.14^{* *}$ & $-.12^{* *}$ & $.54^{* *}$ & 1 & & & & & & & & & & & \\
\hline 8.EXT1 & $.18^{* *}$ & $.20^{* *}$ & $.20^{* *}$ & $.19^{* *}$ & $.21^{* *}$ & $-.17^{* *}$ & .02 & 1 & & & & & & & & & & \\
\hline 9.EXT2 & $.31^{\prime \prime}$ & $.31^{*}$ & $.34^{* *}$ & $.33^{* *}$ & $.33^{* *}$ & $-.19^{* *}$ & -.02 & $.65^{\circ}$ & 1 & & & & & & & & & \\
\hline 10.ЕXT3 & $.21^{*}$ & $.22^{* *}$ & $.23^{* *}$ & $.22^{* *}$ & $.23^{* *}$ & $-.19^{* *}$ & .03 & $.69^{*}$ & $.69^{\prime *}$ & 1 & & & & & & & & \\
\hline 11.OPEN1 & $.19^{*}$ & $.22^{* *}$ & $.20^{* *}$ & $.21^{*}$ & $.17^{* *}$ & $-.10^{*}$ & -.05 & $.42^{* *}$ & $.49^{\prime *}$ & $.43^{* *}$ & 1 & & & & & & & \\
\hline 12.0PEN2 & $.24^{* *}$ & $.25^{* *}$ & $.22^{* *}$ & $.24^{*}$ & $.24^{* *}$ & $-.15^{* *}$ & $-.08^{* *}$ & $.42^{*}$ & $.53^{\prime \prime}$ & $.46^{* *}$ & $.51^{*}$ & 1 & & & & & & \\
\hline 13.AGRE1 & $.15^{*}$ & $.18^{* *}$ & $.18^{* *}$ & $.17^{* *}$ & $.20^{* *}$ & $-.25^{* *}$ & $-.23^{* *}$ & $.22^{* *}$ & $.25^{\prime \prime}$ & $.29^{* *}$ & $.24^{* *}$ & $.33^{* *}$ & 1 & & & & & \\
\hline 14.AGRE2 & $.09^{*}$ & $.12^{* *}$ & $.10^{*}$ & $.11^{*}$ & $.14^{*}$ & $-19^{*}$ & $-.23^{*}$ & $.12^{*}$ & $.13^{*}$ & $.13^{* *}$ & $.18^{\prime \prime}$ & $.21^{* \prime}$ & $.55^{\circ *}$ & 1 & & & & \\
\hline 15.AGRE3 & $.10^{* *}$ & $.12^{* *}$ & $.12^{* *}$ & $.11^{* *}$ & $.14^{* *}$ & $-.16^{* *}$ & $-.16^{*}$ & $19^{*}$ & $.19^{\prime *}$ & $.21^{* *}$ & $.21^{*}$ & $.28^{*}$ & $.47^{* *}$ & $.52^{* *}$ & 1 & & & \\
\hline 16.CONS1 & $.33^{*}$ & $.29^{*}$ & $.35^{*}$ & $.34^{* *}$ & $.37^{* *}$ & $-.17^{* *}$ & $-.07^{\circ}$ & $.23^{* *}$ & $.41^{*}$ & $.22^{* *}$ & $.23^{\prime \prime}$ & $.26^{*}$ & $.24^{*}$ & $.32^{*}$ & $.22^{*}$ & 1 & & \\
\hline 17.CONS2 & $.33^{* \prime}$ & $.29^{* *}$ & $.33^{* *}$ & $.33^{* *}$ & $.35^{* \prime}$ & $-.15^{* *}$ & $-.06^{\circ}$ & $.27^{\prime \prime}$ & $.45^{\prime \prime}$ & $.25^{* *}$ & $.27^{*}$ & $.30^{*}$ & $.20^{* *}$ & $.26^{*}$ & $.19^{* *}$ & $.67^{* *}$ & 1 & \\
\hline 18.ACHIE & $.33^{*}$ & $.26^{*}$ & $.33^{* *}$ & $.33^{* *}$ & $.31^{* *}$ & -.04 & -.01 & .02 & $.11^{\prime \prime}$ & .04 & .03 & .05 & .04 & $.11^{*}$ & .03 & $.30^{\circ}$ & $.23^{*}$ & $\frac{1}{1}$ \\
\hline
\end{tabular}

${ }^{*} \mathrm{p}<.05 ;{ }^{* *} \mathrm{p}<.01$.

Note: MET5P1 $=1$. parcel of metacognition; MET5P2 $=2$. parcel of metacognition; MET5P3= 3 . parcel of metacognition; MET5P4 $=4$. parcel of metacognition; MET5P5 $=5$. parcel of metacognition; NEU1=1. parcel of emotional instability; NEU2=2. parcel of emotional instability ; EXT1= 1. parcel of extraversion; EXT2 $=2$. parcel of extraversion; EXT3=3. parcel of extraversion; OPEN1 $=1$. parcel of openness to experience; OPEN2=2. parcel of openness to experience; AGRE1 $=1$. parcel of agreeableness; AGRE2 $=2$. parcel of agreeableness; AGRE3 $=3$. parcel of agreeableness; $\mathrm{CONS1}=1$. parcel of responsibility; $\mathrm{CONS2}=2$. parcel of responsibility

According to Table 3, it is seen that the relationships among the parcels forming the metacognition, the parcels forming the personality and academic achievement are significant, and there is no multicollinearity in the correlation values.

\section{Findings Related to the Measurement Model}

The standardized path coefficients of the measurement model are given in Figure 1. 


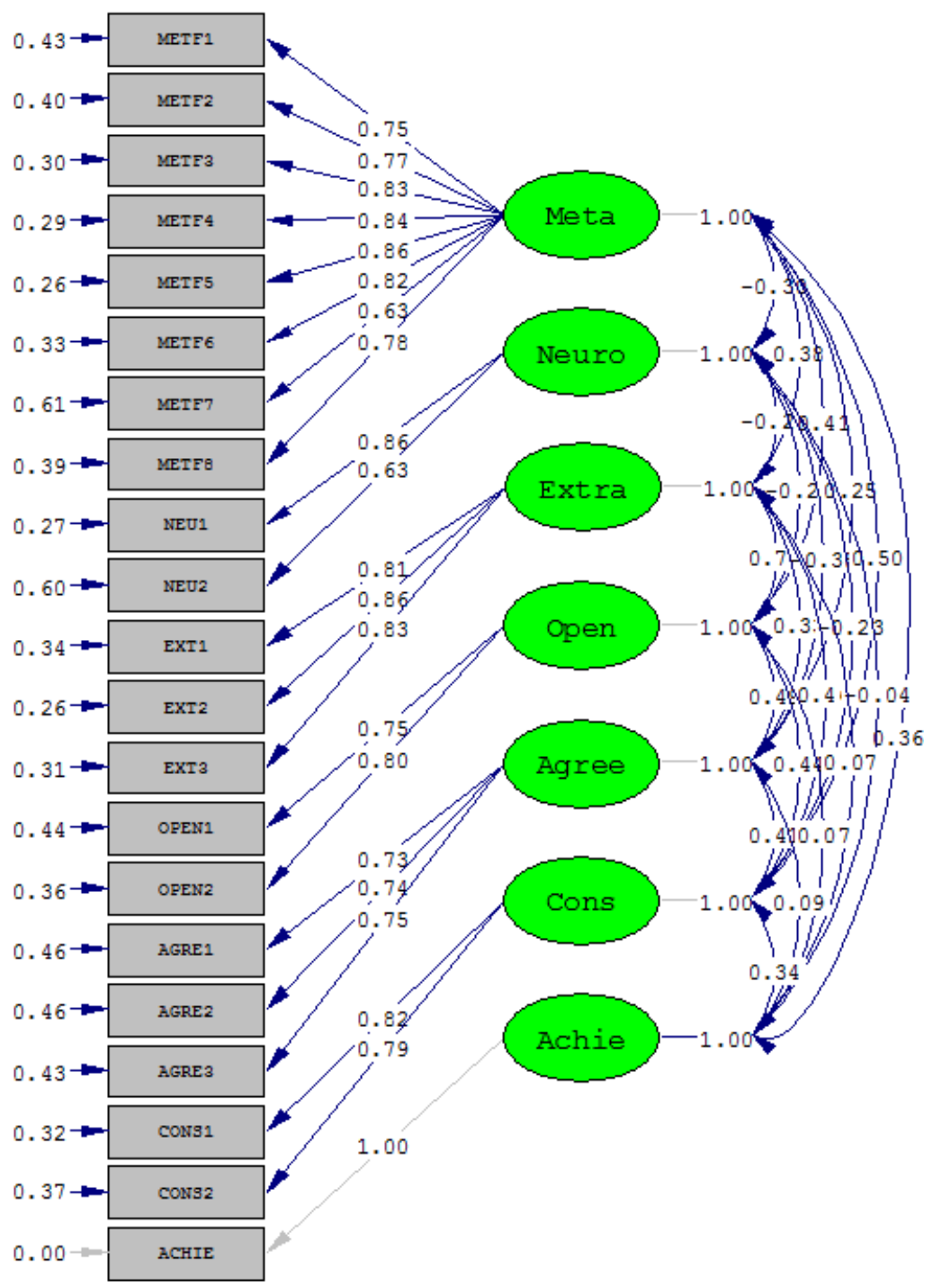

Figure 1. The Standardized Path Coefficients Related to the Measurement Model

When the standardized path coefficients of the measurement model in Figure 1 are examined, it is seen that the relationships between the latent variables and the observed variables are high, and the error variances of the observed variables are low. This finding shows that the measurement model is compatible and acceptable with the data collected in the study. The $t$ values showing the statistical significance of the standardized path coefficients of the measurement model are presented in Figure 2. 


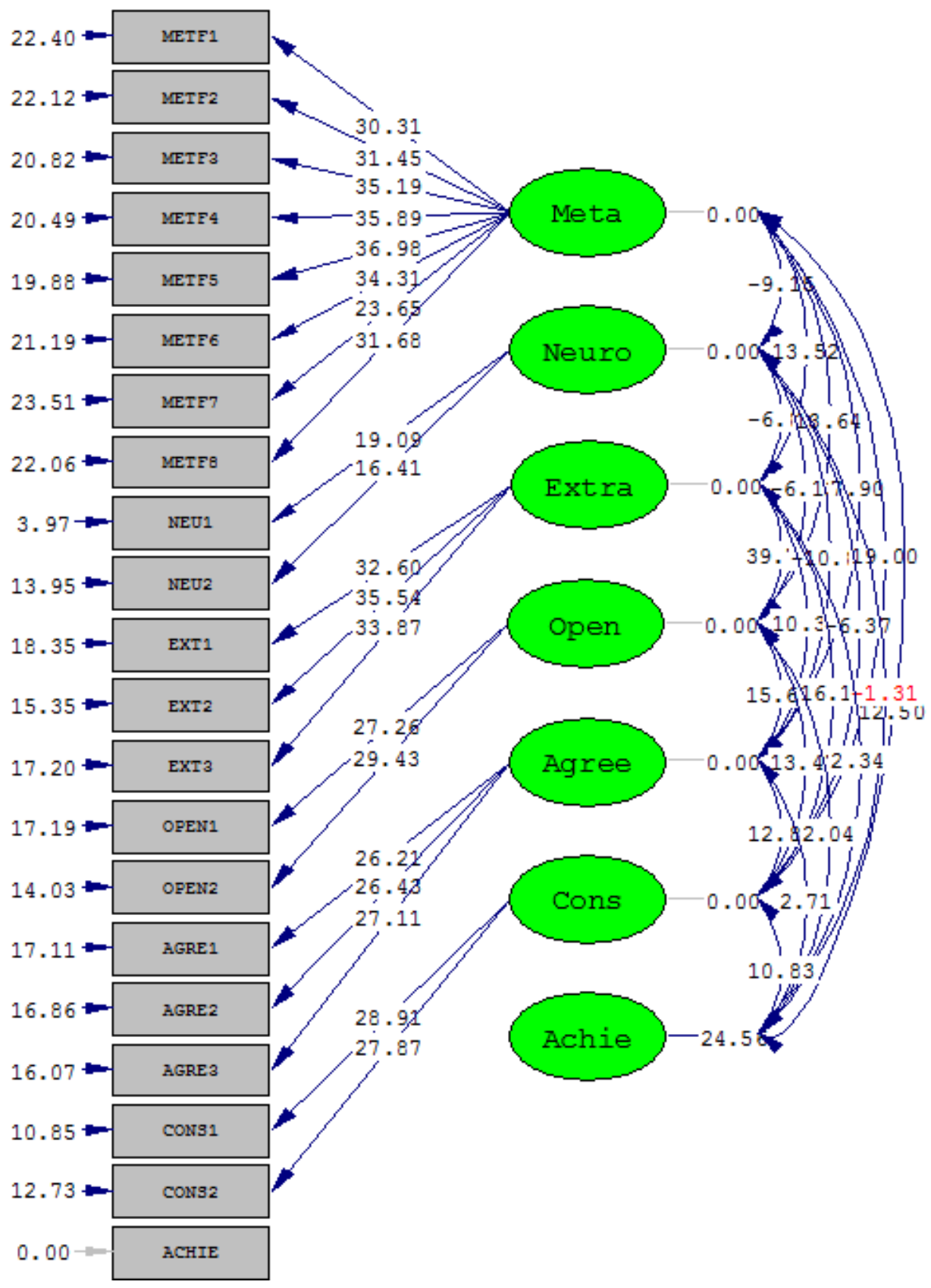

Figure 2. $t$ Values of the Factors in the Measurement Model

As seen in Figure 2, the $t$ values of the latent variables explaining the observed variable are shown on the arrows. Parameter estimates are significant at the .05 level if $t$ values exceed 1.96 and at the .01 level if they exceed 2.56. In this sense, it is seen that all of the paths from latent variables to observed variables are significant at the .01 level. 
In order for the measurement model used in the research to be accepted as a whole, the goodness of fit values should be between certain intervals. Since each of the fit indices evaluating the goodness of fit between the theoretical structure and the collected data has strengths and weaknesses, it is necessary to look at more than one fit indices. In this study, RMSEA, NFI, NNFI, CFI, IFI, SRMR, GFI, AGFI indexes, which are the most frequently used goodness-of-fit indices in the literature, are included. In Table 4 below, the acceptance criteria of various goodness-of-fit indices commonly used in determining model fit and the goodness-of-fit values obtained in this study are presented.

Table 4

Goodness of Fit Indices Related to the Measurement Model

\begin{tabular}{llc}
\hline Fit Index & $\begin{array}{l}\text { Acceptance } \\
\text { Criterion }\end{array}$ & $\begin{array}{c}\text { Goodness of Fit } \\
\text { Indices Related to } \\
\text { the Measurement } \\
\text { Model }\end{array}$ \\
\hline $\begin{array}{l}\text { Root Mean Square Error of Approximation } \\
\text { (RMSEA) }\end{array}$ & $\leq .08$ & .07 \\
90 Percent Confidence Interval for RMSEA & $\leq .08$ & $(.06 ; .07)$ \\
Normed Fit Index (NFI) & $\geq .90$ & .97 \\
Non-Normed Fit Index (NNFI) & $\geq .90$ & .97 \\
Comparative Fit Index (CFI) & $\geq .90$ & .97 \\
Incremental Fit Index (IFI) & $\geq .90$ & .97 \\
\hline Standardized RMR & $\leq .08$ & .04 \\
Goodness-of-fit Index (GFI) & $\geq .90$ & .93 \\
Adjusted Goodness-of-fit Index (AGFI) & $\geq .90$ & .90 \\
\hline
\end{tabular}

When the goodness of fit statistics of the measurement model are evaluated, all values meet the acceptance criteria, in other words, the goodness of fit statistics show that this model is supported at an acceptable level by the data as a whole. According to these findings, the measurement model was confirmed.

\section{Findings Related to the Structural Equation Model}

In the first stage of the two-stage structural equation study adopted in the research, a very good measurement model was created in terms of goodness-of-fit statistics. In the second stage, a structural model that explains the structural relationships between the latent variables in the model was created and tested. Below are the standardized path 
coefficients of the structural model, the t-values of whether these coefficients are significant or not, and the model goodness indices showing whether the model can be accepted as a whole.

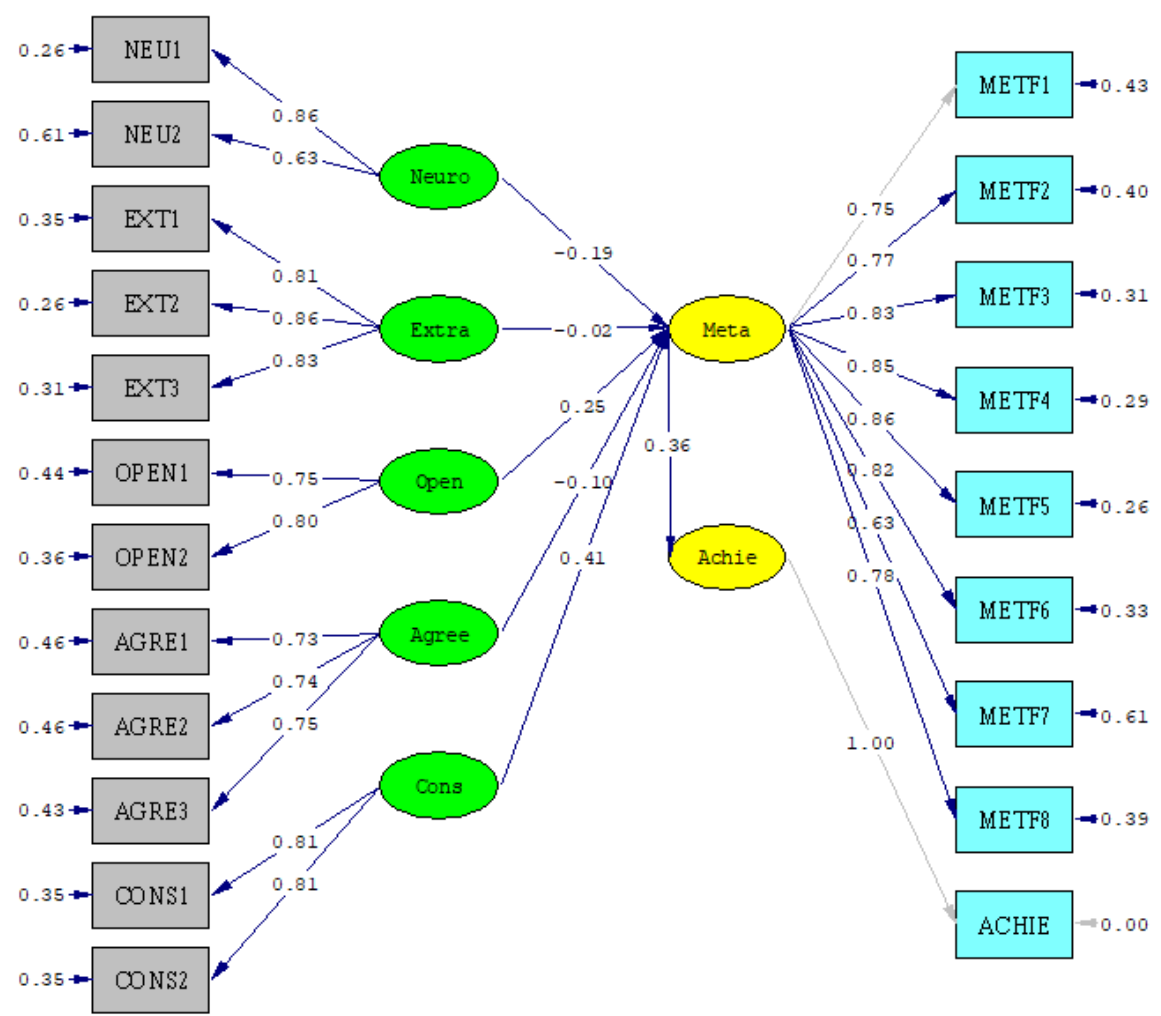

Figure 3. Standardized Path Coefficients of the Structural Equation Model

When the standardized path coefficients showing the relationships between personality factors and metacognition are examined, the responsibility (Sorum) factor affects metacognition the most, followed by openness to experience (Dacik), emotional instability (Dden) and agreeableness (Yubas), and the lowest path coefficient is seen in extraversion (Ddon). It is seen that emotional instability, in other words neuroticism and agreeableness, have a negative effect on metacognition, while other factors have a positive effect. In the model, it is seen that the path from metacognition to success has a path coefficient of .36 . The $t$ values for the statistical significance of the standardized path coefficients of the structural model are presented in Figure 4. 


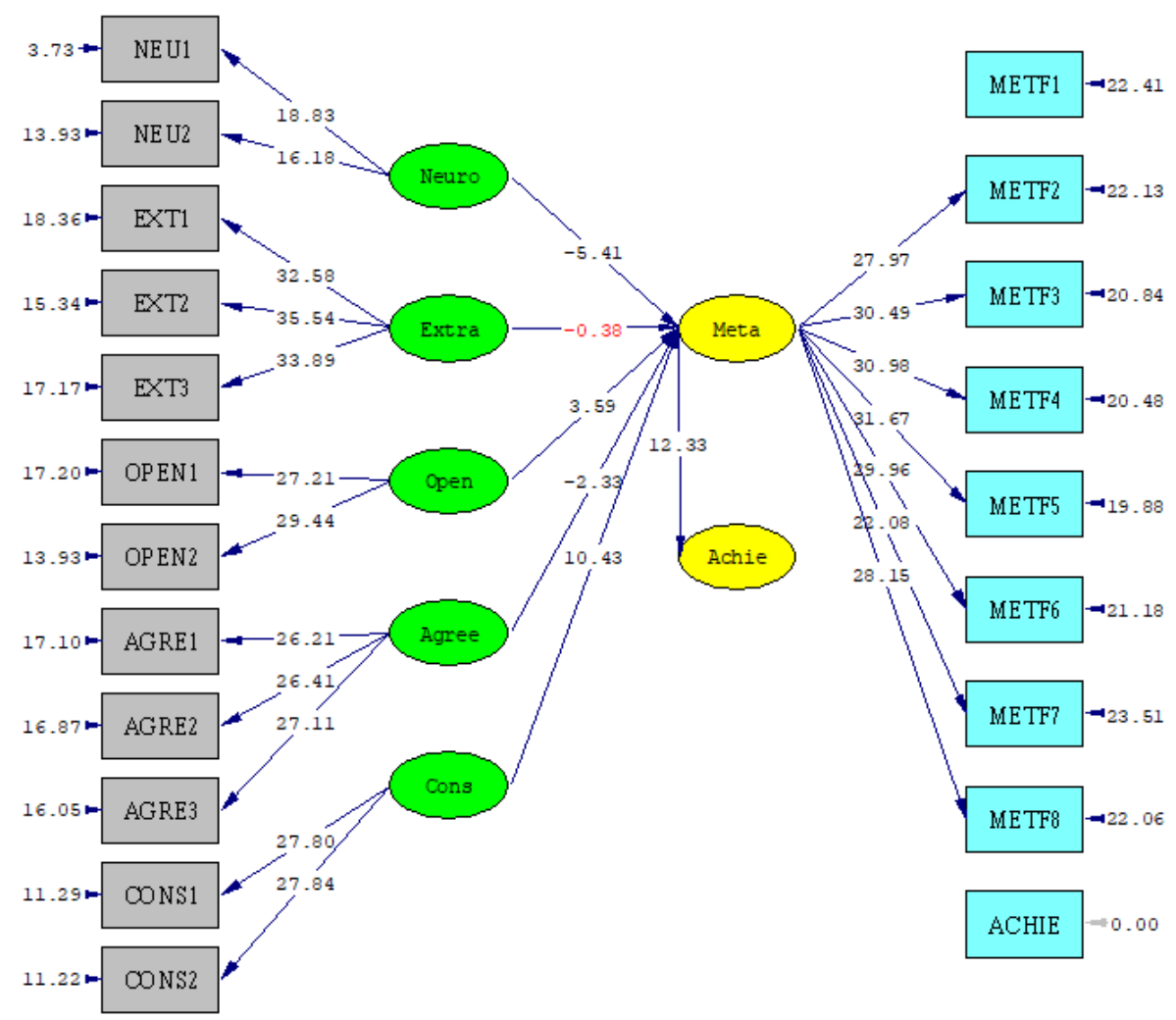

Figure 4. $t$ Values Related to the Structural Equation Model

As seen in Figure 4, the t-value of the path from personality dimensions from extraversion to metacognition is not statistically significant. Therefore, the extraversion dimension was removed from the model and the model was retested. The standardized path coefficients of the new model created, the t-values regarding whether these coefficients are significant and the goodness of fit indices showing whether the model will be accepted as a whole are given below. 


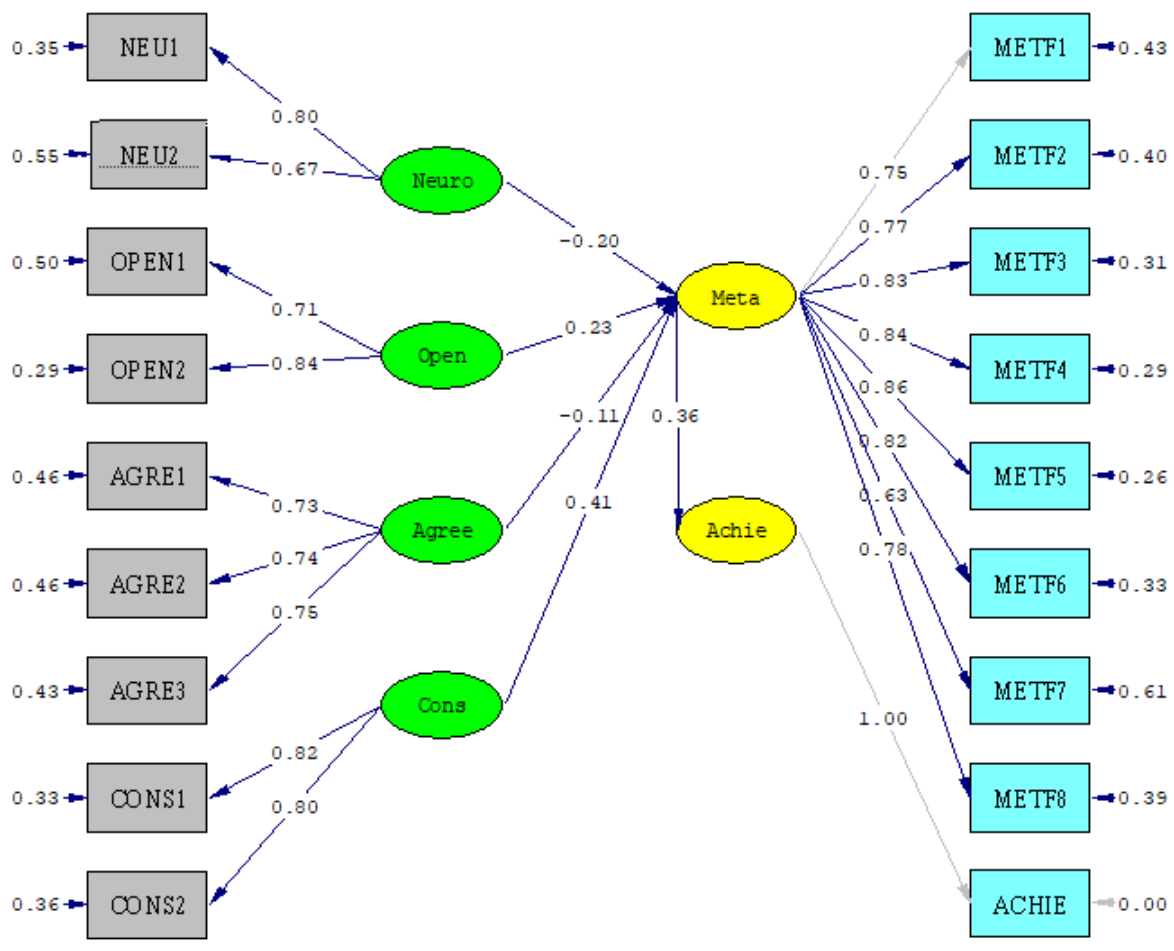

Figure 5. Standardized Path Coefficients of the Structural Equation Model after the Removal of the Extraversion Dimension

According to the path diagram in Figure 5, the path between responsibility which is one of the sub-dimensions of personality and metacognition has a coefficient of .41, the path between agreeableness and metacognition has a coefficient of -.11, the path between openness to experience and metacognition has a coefficient of .23, and the path between emotional instability and metacognition has a coefficient of -.20 . The coefficient of the path from metacognition to success is .36 . The $t$ values regarding whether the above coefficients are significant or not are given in Figure 6. 


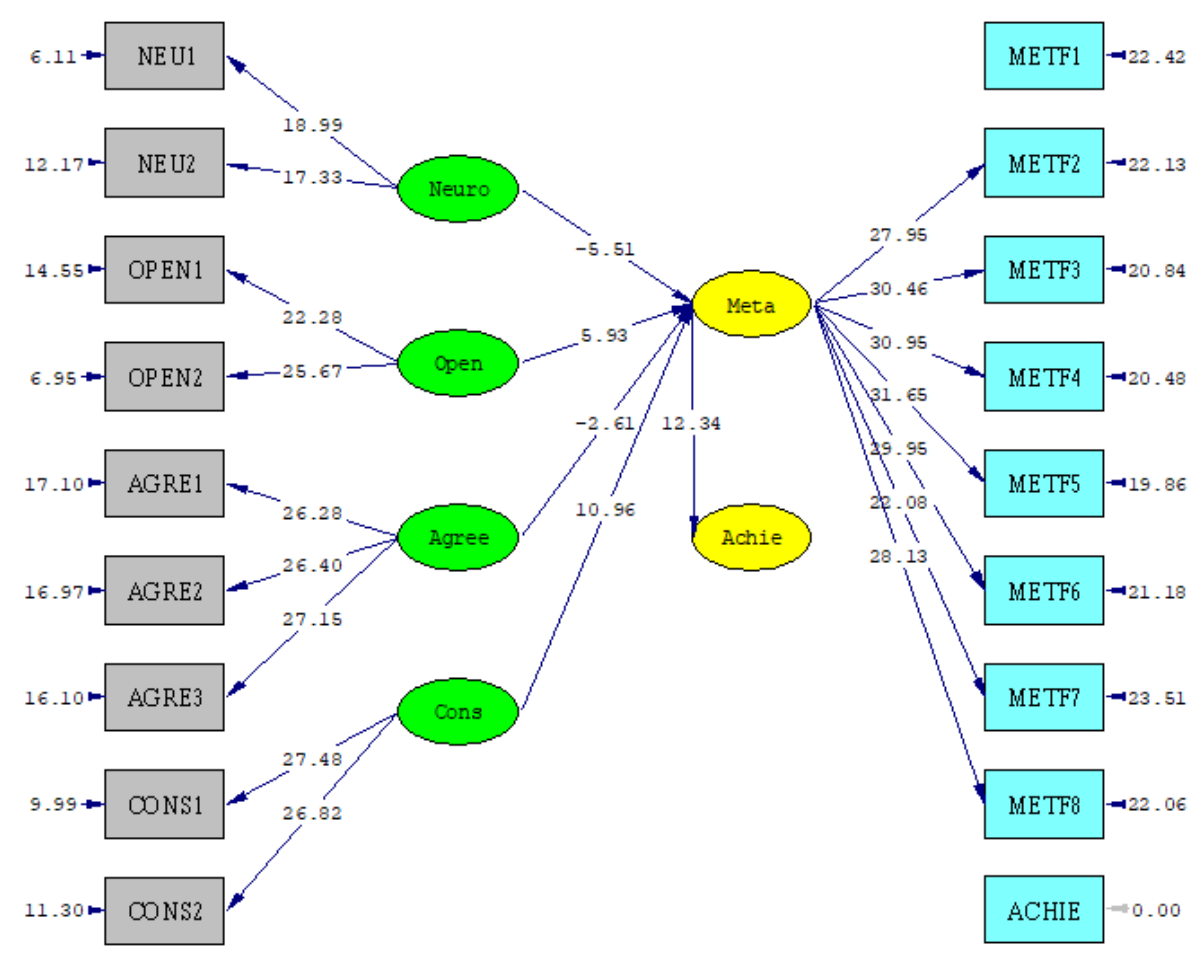

Figure 6. $t$ Values for the Structural Equation Model Resulting after the Removal of the Extraversion Dimension

When the t values of the structural equation model shown in Figure 6 are examined, it is seen that all paths from personality to metacognition and from metacognition to academic success are significant at the .01 level.

\section{Goodness of Fit Indices of the Structural Equation Model}

Information on the criteria of the fit indices that evaluate the goodness of fit between the theoretical structure and the collected data and the goodness of fit values of the structural model are presented in Table 5. 
Table 5

Goodness of Fit Indices Related to the Structural Equation Model

\begin{tabular}{llc}
\hline Fit Index & $\begin{array}{l}\text { Acceptance } \\
\text { Criterion }\end{array}$ & $\begin{array}{c}\text { Goodness of Fit } \\
\text { Indices Related to } \\
\text { the Structural } \\
\text { Equation Model }\end{array}$ \\
\hline $\begin{array}{l}\text { Root Mean Square Error of Approximation } \\
\text { (RMSEA) }\end{array}$ & $\leq .08$ & .07 \\
90 Percent Confidence Interval for RMSEA & $\leq .08$ & $. .06 ; .07)$ \\
Normed Fit Index (NFI) & $\geq .90$ & .97 \\
Non-Normed Fit Index (NNFI) & $\geq .90$ & .97 \\
Comparative Fit Index (CFI) & $\geq .90$ & .97 \\
Incremental Fit Index (IFI) & $\geq .90$ & .97 \\
Standardized RMR & $\leq .08$ & .04 \\
Goodness-of-fit Index (GFI) & $\geq .90$ & .93 \\
Adjusted Goodness-of-fit Index (AGFI) & $\geq .90$ & .91 \\
\hline
\end{tabular}

The goodness-of-fit statistics given in Table 5 show that this model is supported at an acceptable level by the data as a whole. All the relationships stated by the model are quite high and significant, hence the constructed model has been confirmed.

\section{Structural Equations Between Personality Factors and Metacognition}

According to the structural model presented in Figure 5, the structural equations regarding the amount of emotional instability, openness to experience, agreeableness, and responsibility explain the variance in students' metacognitive level are as follows: Metacognition $=-.20 *$ Emotional instability $+.23 *$ Openness to experience +- . $11^{*}$ Agreeableness $+.41 *$ Responsibility, Errorvar. $=.67, \mathrm{R}^{2}=.33$

According to these values, students' personality traits explain $33 \%$ of the variance in their metacognition. In other words, $1 / 3$ of metacognition is predicted by personality factors. Accordingly, personality is an important descriptor of metacognition. When the $t$ values of the obtained data presented in Figure 6 are examined for the significance levels, it is seen that among the factors of emotional instability $(t=-5.51, p<.05)$, openness to experience $(t=5.93, \mathrm{p}<.05)$, agreeableness $(t=-2.61, \mathrm{p}<.05), \mathrm{p}<.05)$, and responsibility $(t=10.96, \mathrm{p}<.05)$, responsibility seems to be the most important factor that best explains metacognition. Also, the sum of sub-factors had a t value of $14.22(\mathrm{p}<.05)$. 


\section{Structural Equations Between Metacognition and Academic Achievement}

The degree to which metacognition explains the variance in students' academic achievement, of which $33 \%$ of the total variance is explained by the four factors included in the structural equation model, is as follows: Success $=0.17^{*} \operatorname{Cognitive,~Errorvar.~}=.18$, $\mathrm{R}^{2}=.13$.

Metacognition ( $t=12.34, \mathrm{p}<.05)$ explains .13 of the total variance in students' academic achievement. In other words, metacognition affects academic achievement by $13 \%$.

\section{RESULTS, DISCUSSIONS AND SUGGESTIONS}

The structural equation modeling method was used to investigate the hypothesis that metacognition plays a mediating role in the link between university students' personality traits and academic achievement. Personality factors explained $33 \%$ of the variance in metacognition, while metacognition explained $13 \%$ of the variance in academic achievement, according to the analyses conducted to assess the mediating function. According to the findings, it was seen that the relationship between personality and academic achievement was established through metacognition, in other words, metacognitive processes had a mediating role in the relationship between personality dimensions and achievement. According to this finding, the research hypothesis was confirmed. The findings of this study are consistent with the studies which Bidjerano and Dai (2007) found that self-regulated learning strategies, including metacognition, had a partial mediation role in the relationship between personality and achievement, Landine (1994) found a significant positive relationship between metacognition and personality variables and academic achievement, Hayat, Shateri, Amini and Shokrpour (2020) found that metacognitive strategies have a mediating role in the relationship between positive academic feelings and academic success, which are also related to personality traits such as enjoying learning environments, being proud, and hoping.

Bidjerano and Dai (2007) showed that high scores on responsibility and openness to experience of personality are associated with self-regulatory metacognitive skills such as time management, effort organization, elaboration, and critical thinking. Responsibility is significantly related to metacognitive processes such as students' tendencies to manage their learning efforts and structure their time and learning environments. Students with a high level of responsibility and who describe themselves as collaborators are likely to have a designated place to work or choose a place where they can focus more and manage their study time skillfully and make good use of it. The empirical link between openness to experience and elaboration, critical thinking and metacognition is conceptually significant as well. Students' tendency to critically evaluate information, reflect on their own learning, and think about their own thoughts while performing a task is partially explained by the way they receive and process information, in other words, by metacognitive processes (Bidjerano \& Dai, 2007). 
The finding in this study that responsibility positively affects academic achievement is consistent with the studies which Furnham, Chamorro-Premuzic, and McDougall (2003) found that there is a positive relationship between responsibility and academic performance, and that the most powerful predictor of academic achievement among the five major factors that make up personality is the dimension of responsibility; Busatoa, Prinsb, Elshouta, and Hamakera (2000) found that the responsibility factor positively affects success; Pang (2008) states that there is a positive correlation between responsibility and academic grade point average (GPA), and that responsibility is the strongest predictor of success among the five major personality factors; Letourneau (2009) states that responsibility has a positive correlation with success; Noftle and Robins (2007) found that the responsibility factor was the strongest predictor of success in high school and university grade point averages; De Raad and Schouwenburg (1996) found that responsibility is the dimension most associated with academic achievement.

The indirect effect of the personality's openness to experience dimension on academic achievement is positive. Findings obtained within the scope of this sub-dimension are consistent with the studies which Noftle and Robins (2007) found that openness factor of personality is the strongest indicator of success in Scholastic Aptitude Test (SAT) oral exam scores; Pang (2008) and Letourneau (2009) stated that there is a positive correlation between openness to experience and success; De Raad and Schouwenburg (1996) found that openness to experience is one of the three dimensions most associated with the educational environment; while they are inconsistent with the research findings which De Fruyt and Mervielde (1996) found that there is a negative relationship between openness and achievement, and Busatoa, Prinsb, Elshouta, and Hamakera (2000) put forth that openness to experience is not significantly associated with academic achievement.

The agreeableness or compatibility dimension was found to be negatively associated with academic achievement in this study. While this finding is consistent with research findings (Slaats et al., 1997; Vermetten, Lodewijks, Vermunt, 2001) that there is a positive correlation between agreeableness and superficial (memorization) learning, that there is a positive relationship between agreeableness and academic grade point average (GPA) (Pang, 2008); it is not in line with the findings of Busatoa, Prinsb, Elshouta, and Hamakera (2000) and Letourneau (2009) who found that agreeableness is not significantly associated with academic achievement. According to other factors of personality, previous findings regarding the effect of agreeableness on academic achievement differ. In the structural equation modeling established in this study, when the effects on metacognition and thus achievement were examined, it was found that the lowest path coefficient belonged to this factor.

De Raad and Schouwenburg (1996) found that students with high emotional instability, especially at university level, are more handicapped than students with low level of emotional instability. Chamorro-Premuzic and Furnham ( 2003) found that emotional instability decreased academic achievement. Pang (2008) put forth that there is a 
negative correlation between emotional instability and success. The finding of this study which states that the emotional instability (neuroticism) factor of personality negatively affects academic achievement is consistent with those findings. In general, the effect of emotional instability on success is negative rather than positive (Matthews \& Zeidner, 2004).

The following recommendations can be made according to the results obtained in the study.

1. The sample of this study includes only university students. Repetition of the research at different teaching levels may contribute to the generalizability of the results.

2. New studies investigating the mediation and regulatory effects of variables such as motivation, goal orientations, self-efficacy perception, school attachment in models where personality factors are predictors and academic achievement is the outcome variable may contribute to the explanation of a larger part of the variance in academic achievement.

3. School counselors and psychologists can provide consultation services to teachers and administrators in determining the personality traits and metacognitive processes of students and designing learning environments suitable for individual differences.

4. It may be beneficial to teach metacognitive strategies through group guidance activities and also to provide psychological counseling, especially to students who are determined to have a high level of emotional instability.

\section{References}

Atkinson, R. L., Atkinson, R. C., Smith, E. E, Bem, D. J., \& Nolen-Hoeksema, S. (1996). Psikolojiye giriş [Introduction to psychology]. (Trans. Yavuz Alagon). A Ankara: Arkadaş Yayınları.

Akın, A., Abacı, R., \& Çetin. B. (2007). Bilişötesi farkındalık Envanteri'nin türkçe formunun geçerlik ve güvenirlik çalışması [The validity and reliability study of the Turkish form of the Metacognitive Awareness Inventory]. Kuram ve Uygulamada Eğitim Bilimleri, 7(2), 655-680

Bacanll, H., İlhan, T., \& Aslan, S. (2009). Beş faktör kuramına dayalı bir kişilik ölçeğinin geliştirilmesi: Sıfatlara dayalı kişilik testi [Development of a personality scale based on the five factor theory: Adjective personality test]. Türk Eğitim Bilimleri Dergisi, 7(2), 261-279.

Balcl, A. (2009). Sosyal bilimlerde araştırma yöntem, teknik ve ilkeler [Research methods, techniques and principles in social sciences]. Ankara: Pegem Akademi.

Barrick, M. R., \& Mount, M.K. (1991). The big five personality dimensions and job performance: A meta-analysis. Personnel Psychology, 44, 1-26

Bidjerano, T., \& Yun Dai, D. (2007). The relationship between the big-five model of personality and self-regulated learning strategies. Learning and Individual Differences 17, 69-81

Burger, M. J. (2006). Kişilik [Personality] (Trans. İ. D. Erguvan Sarığlu). İstanbul: Kaknüs Yayınları 
Busato, V., Prins F. J., Elshout, J.J., \& Hamaker, C. (2000). Intellectual ability, learning style, personality, achievement motivation and academic success of psychology students in higher education. Personality and Individual Differences, 29, 1057-1068

Chamorro-Premuzic, T., \& Furnham, A. (2003). Personality traits and academic examination performance. European Journal of Personality, 17, 237-250

Costa, P., \& McCrae, R. (1992). Normal personality assesment in clinic pratice: The NEO personality inventory. Psychological Assesment, 4(1), 5-13.

De Fruyt, F., \& Mervielde, I. (1996). Personality and interests as predictors of educational streaming and achievement. European Journal of Personality, 10, 405-425.

De Raad, B., \& Schouwenburg, H. C. (1996). Personality in learning and education: a review. European Journal of Personality, 10, 303-336.

Desoete, A., \& Roeyers, H. (2002). Off-line metacognition - A domain-specific retardation in young children with learning disabilities. Learning Disability Quarterly, 25, 123-139.

Diseth, A. (2003). Personality and approaches to learning as predictors of academic achievement. European Journal of Personality, 17, 143-155.

Duff, A., Boyle, E., Dunleavy, K., \& Ferguson, J. (2004). The relationship between personality, approach to learning and academic performance. Personality and Individual Differences, 36, $1907-1920$

Dunlosky, J., \& Thiede, K. W. (1998) What makes people study more? An evaluation of factors that affect people's self-paced study and yield "labor-and-gain" effects. Acta Psychologica, 98, 3756.

Entwistle, N. (1988). Motivational factors in students' approaches to learning. R. R. Schmeck (Ed.), Learning Strategies and Learning Styles (ss. 21-51). Plenum Press.

Flavell, J. H. (1976). Metacognitive aspects of problem solving. In L. Resnick (Ed.), The Nature of Intelligence (ss. 231-235). Hillsdale, NJ: Lawrence Erlbaum Associates.

Furnham, A., Chamorro-Premuzic, T., \& McDougall, F. (2003). Personality, cognitive ability, and beliefs about intelligence as predictors of academic performance. Learning and Individual Differences, 14, 49-66

Garner, R., \& Alexander, P. A. (1989). Metacognition: Answered and unanswered questions. Educational Psychologist, 24, 143-158.

Hayat, A.A., Shateri, K., Amini, M., \& Shokrpour, N. (2020). Relationships between academic selfefficacy, learning-related emotions, and metacognitive learning strategies with academic performance in medical students: a structural equation model. BMC Medical Education, 20, 76. https://doi.org/10.1186/s12909-020-01995-9

Jacobs, J. E., \& Paris, S. G. (1987). Children's metacognition about reading: Issues in definition, measurement, and instruction. Educational Psychologist, 22, 255-278.

Kelly, D., \& Donaldson, D. (2016) Investigating the complexities of academic success: Personality constrains the effects of metacognition. Psychology of Education Review, 40(2), 17-24

Landine, J. R. (1994). Relationship between metacognitive approaches, motivation, locus of control, self-efficacy and academic achievement. (Unpublished Master Thesis) New Brunswick: The University of New Brunswick.

Letourneau, Ruth M. (2009). Predicting college success: Big five. (Unpublished Dissertation). Fullerton: Master of Arts in Psychology Faculty of California State University. 
Matthews, G. (1997). Extroversion, emotion, and achievement: A cognitive-adaptive model. G. Matthews (Ed.), Cognitive Science Perspectives on Personality and Emotion (ss. 339-442). Amsterdam: Elsevier.

Matthews, G., \& Zeidner, M. (2004). Traits, states, and trilogy of mind: An adaptive perspective on intellectual functioning. D. Y. Dai ve R. J. Sternberg (Ed.), Motivation, emotion, and cognition: Integrative perspectives on intellectual functioning and development (ss. 143-174). Mahwah, NJ: Lawrence Erlbaum.

McCrae, R. R., \& Costa, P. T. (1987). Validation of the five-factor model of personality across instruments and observers. Journal of Personality and Social Psychology, 52(1), 81-90.

McCrae, R., \& Costa, P. (1988). From catalog to classification: Murray's needs and five factor model. Journal of Personality and Social Psychology, 55(2), 258-265.

Noftle, E. E., \& Robins, R. W. (2007).Personality predictors of academic outcomes: Big five correlates of GPA and SAT scores. Journal of Personality and Social Psychology, 93(1), 116-130.

Pang, H. H. P. (2008). Big five personality traits and parental involment: contributing as predictors of academic performance in high school and college. (Unpublished Dissertation for the degree of Doctor of Psychology). California: Alliant International University California School of Professional Psychology.

Paris, S. G., \& Winograd, P. (1990). Promoting metacognition and motivation of exceptional children. Remedial and Special Education, 11(6), 7-15.

Pintrich, P. R. (2000). Multiple goals, multiple pathways: The role of goal orientation in learning and achievement. Journal of Educational Psychology, 92(3), 44-555

Poropat, A. E. (2009). A meta-analysis of the five-factor model of personality and academic performance. Psychological Bulletin, 135(2), 322-338. https://doi.org/10.1037/a0014996

Slaats, A., van der Sanden, J., \& Lodewijks, H. (1997). Relating personality characteristics and learning style factors to grades in vocational education. Paper presented at the Annual Meeting of the American Educational Research Association, Chicago, IL.

Schraw, G.(1998). Promoting general metacognitive awareness. Instructional Science, 26(1-2), 113-125.

Somer, 0., Korkmaz, M., \& Tatar, A. (2004). Kuramdan uygulamaya beş faktör kişilik modeli ve beş faktör kişilik envanteri (5FKE) [Five factor personality model and five factor personality inventory (5FPI) from theory to practice]. İzmir : Ege Üniversitesi Basımevi.

Sorić, I., Penezić, Z., \& Burić, I. (2017). The Big Five personality traits, goal orientations, and academic achievement. Learning and Individual Differences, 54, 126134. https://doi.org/10.1016/j.lindif.2017.01.024

Sleep, C. E., Lynam, D. R., \& Miller J. D. A. (2020). Comparison of the validity of very brief measures of the big five/five-factor model of personality. Assessment, 28(3),739-758. doi: $10.1177 / 1073191120939160$.

Vermetten, Y.J., Lodewijks, H.G., \& Vermunt, J.D. (2001). The role of personality traits and goal orientations in strategy use. Contemporary Educational Psychology, 26, 149-170.

Wells, A., \& Cartwright-Hatton, S. (2004). A short form of the metacognitions questionnaire: Properties of the MCQ-30. Behaviour Research and Therapy, 42(4), 385-396. https://doi.org/10.1016/S0005-7967(03)00147-5 
Ethics committee approval for this study was obtained from Düzce University Scientific Research and Publication Ethics Committee, dated 26.08.2021 and numbered 2021/203.

\section{Statement of Contribution of Researchers to the Article:}

1st author contribution rate: $50 \%$

2nd author contribution rate: $50 \%$

\section{Conflict of Interest Statement:}

There is no conflict of interest.

Statement of Financial Support or Acknowledgment:

No financial support was received from any institution for this study. 
